\title{
Preservação da natureza e desenvolvimento rural: dilemas e estratégias dos agricultores familiares em Áreas de Proteção Ambiental
}

\section{The preservation of nature and rural development: dilemmas and strategies of family farmers in Areas of Environmental Protection}

\author{
Magda M. ZANONI*, Angela Duarte D. FERREIRA, Lovois de A. MIGUEL**, \\ Dimas FLORIANI, Naldy CANALI, Claude RAYNAUT
}

\begin{abstract}
"Nós sempre caçamos e tiramos da floresta o que era preciso para viver: as plantas para remédio, a carne para comer, a madeira para fazer a casa. E a floresta continua aí porque fomos nós que preservamos. Nós somos os mais ecológicos de todos porque usamos sem destruir. Mas os que vem falar de meio ambiente agora pensam que ser ecológico é matar os homens de fome ou mandar todos embora daqui para não atrapalhar as árvores e o micoleão-dourado."
\end{abstract}

(Entrevista 4, novembro de 1999)".

\begin{abstract}
RESUMO
No âmbito da discussão sobre os dilemas entre preservação da natureza e desenvolvimento, este texto procura analisar a especificidade da agricultura familiar numa Área de Proteção Ambiental onde os agricultores e demais moradores do meio rural são submetidos a leis restritivas do uso agrícola e extrativista. A pesquisa atualmente em andamento na APA que abrange o município de Guaraqueçaba, litoral norte do Paraná - Brasil, busca compreender como estes agricultores e moradores procuram assegurar a sua reprodução social tanto pelo manejo do patrimônio cultural local como por adaptações e mudanças de seu modo de vida, buscando interagir e fazer face às transformações atuais do seu ambiente socioeconômico e aos impasses criados pela legislação ambiental.
\end{abstract}

* Maitre de Conférences na Université Paris 7 - Denis Diderot. E-mail : Zanoni.holos@ wanadoo.fr

** Professor do Departamento de Economia e do Programa de Pós Graduação em Desenvolvimento Rural - UFRGS. E-mail: Lovois@vortex.ufrgs.br 


\begin{abstract}
As a part of ongoing discussions on dilemmas regarding the preservation of nature and development, this text seeks to analyze the specificity of family farming in an Area of Environmental Protection where farmers and other residents are submitted to legislation restricting agriculture and extractive activities. This ongoing research is being carried out in the Area of Environmental Protection that covers the municipality of Guaraqueçaba, on the northern coast of the state of Paraná. It aims to shed light on how these farmers and residents guarantee their own social reproduction, both through the use of local cultural patrimony and through adaptations and changes in their way of life, interacting with and confronting ongoing changes in their socio-economic environment and the impasses that have arisen from environmental legislation.
\end{abstract}

A discussão sobre preservação e desenvolvimento atualmente em voga na literatura sobre as relações sociedade/natureza não tem tido ressonância nos estudos rurais e agrários em geral, salvo quando se trata da temática da agricultura sustentável. Nesse contexto, cabe ressaltar que poucos estudos e pesquisas sobre a especificidade da agricultura familiar e sobre as transformações pelas quais passam estes agricultores quando submetidos a leis de proteção ambiental restritivas do uso agrícola foram implementados até o presente momento. A pesquisa atualmente em andamento na Área de Proteção Ambiental que abrange o município de Guaraqueçaba, litoral norte do Paraná - Brasil, busca, de uma certa maneira, suprir estas lacunas visando compreender como agricultores familiares implantados nesta região procuram assegurar a sua reprodução social, quais as heranças de que se apropriam do passado e adaptações ou mudanças que realizam para interagir com os novos impasses criados pela legislação ambiental que regulamenta o uso de seu território.

Este texto introduz algumas reflexões que norteiam esta pesquisa, cujo levantamento preliminar será concluído no decorrer do ano $2000^{1}$ e apóiase igualmente em resultados de um programa de pesquisa já concluído (1989-97)².

\section{Modernidade, desenvolvimento e preser- vacionismo}

A modernidade, não sem razão, vem sendo assimilada ao sintoma negativo de destruição da natureza (Giddens, 1997). Um signo dessa representação é a forma como foi construído o conceito de desenvolvimento, isto é, como sinônimo de crescimento econômico, submetendo os recursos naturais à lógica de apropriação do sistema industrial, tanto capitalista quanto estatista (Castells, 1999).

Nos últimos vinte anos, porém, as sociedades e as agências governamentais, nacionais e internacionais, começaram a desconstruir algumas certezas sobre as possibilidades ilimitadas de crescimento, de produção e distribuição de riquezas. A assimetria desse modelo dominante de apropriação dos recursos naturais produz distorções crescentes e em escala planetária. Seus efeitos fazem-se sentir pelo aumento da degradação ambiental, tanto nos aspectos naturais (esgotamento dos recursos não renováveis, poluição dos recursos hídricos e do ar, agressão à biodiversidade), quanto sociais (concentração da riqueza em alguns países e aumento da miséria nos países periféricos).

Apesar dos generalizados debates e apelos, de diferentes conteúdos, por um desenvolvimento sus-

\footnotetext{
${ }^{1}$ Programa de Pesquisa em Áreas Rurais de Guaraqueçaba - Desenvolvimento e Preservação da Natureza. Doutorado em Desenvolvimento e Meio Ambiente da Universidade Federal do Paraná/ Universidade de Bordeaux II/ Universidade de Paris VII - CNRS/ França.

${ }^{2}$ Programa de pesquisa Gestão dos recursos naturais para um desenvolvimento sustentável: Area de Proteção Ambiental de Guaraqueçaba. Universidade Paris 7/Association Holos/Universidade Federal do Paraná-PROEC, 1988-1987.
} 
tentável, ainda se está longe de suplantar o conceito de crescimento econômico, pelo menos nos termos em que foi expresso no Relatório Bruntland (1987). Esta noção ainda permanece confinada ao domínio da ética: embora de importância crucial para a convivência humana na contemporaneidade, ela encontra dificuldades reais de se contrapor às lógicas de mercado, surdas aos apelos do comedimento na utilização dos fatores produtivos, principalmente aqueles vinculados aos recursos físicos e naturais.

Profundas divergências sobre a noção de desenvolvimento sustentável subsistem entre pesquisadores e agências de desenvolvimento de diferentes países do mundo. Diante do crescimento das incertezas e do risco em escala planetária, observa-se um certo consenso sobre a constatação de que os recursos naturais são finitos, que não se deve comprometer as gerações presentes e futuras, que se deve combinar crescimento econômico com eqüidade social, etc. Mas a realidade dos fatos econômicos e políticos mostra-se diametralmente oposta. A polêmica entre países do Norte e do Sul, inaugurada pela Eco-92, sobre uma série de questões ambientais ("Convenção da Biodiversidade", "Convenção das Florestas", "Convenção sobre Mudanças Climáticas", financiamento da Agenda 21 e outras) revelou diferenças de controle político de uns países sobre outros, em escala mundial (Leis e Viola, 1995).

Isto suscita, evidentemente, uma questão central: até que ponto a fragilidade dos apelos éticos ao uso adequado dos recursos naturais não cede à ética da conveniência e da impotência, refugiando-se na ideologia do preservacionismo, ao invés de questionar a natureza mesma da lógica do modelo de sociedade, assentada na espoliação da natureza e dos recursos humanos (ou quando não da subutilização ou do total descaso destes últimos)?

Convém situar o "preservacionismo" no domínio das representações sociais, reveladoras de uma determinada visão de natureza e de intervenção humana sobre a mesma. Neste sentido, o "preservacionismo ambiental" pode funcionar como uma ideologia, não no sentido de reflexo da realidade mas principalmente como uma forma de agir sobre o real (Duby, 1976; Godelier, 1984).

$\mathrm{Se}$, por um lado, o preservacionismo pode funcionar como ideologia legitimadora de uma dada concepção de natureza e das relações que as sociedades mantêm com a mesma, por outro, é um espaço de representação simbólica onde atuam forças sociais com diferentes projetos de sociedade e de entendimento do papel da natureza. Disto decorre a acepção pela qual o espaço de construção do sentido social da natureza, da sociedade e de suas mútuas relações se situam na confluência de práticas e de saberes, com diferentes racionalidades ${ }^{3}$.

A pluralidade de concepções de vida, de sociedade e de natureza é uma característica central da modernidade; nesta, há uma sobreposição de distintas temporalidades, de fluxos informacionais e de poderes institucionais, associados a sistemas naturais e sociais abertos (Castells, 1999).

Independentemente das conclusões a tirar dos questionamentos anteriores, as sociedades contemporâneas vêm implementando medidas reguladoras do meio ambiente e criando espaços de preservação natural com a finalidade de viabilizar a vida, em condições de reprodução da biodiversidade dos ecossistemas existentes. Neste sentido, os espaços destinados à proteção da natureza são reservas de proteção à vida e ainda um ensaio de sustentabilidade; laboratórios para repensar as formas de monitoramento e de intervenção e como as sociedades e seus respectivos modelos de desenvolvimento interagem com a natureza. São o resultado de discursos e práticas sobre a natureza e o desenvolvimento social pretendendo estabelecer novas alianças entre ciência, natureza e sociedade (Prigogine, 1986).

\footnotetext{
${ }^{3}$ Utilizamos aqui a noção de racionalidade com um alcance limitado, isto é, voltada ao sentido de racionalização da ação, empregada por Giddens (1989), e não no sentido genérico de lógicas discursivas abstratas: a capacidade que atores competentes têm de se "manterem em contato" com as bases do que fazem, da forma como o fazem, de tal modo que, se interrogados por outros, podem fornecer razões para suas atividades.
} 
No contexto brasileiro, tais espaços de proteção ambiental compreendem várias formas legais, com finalidades diversas em termos protecionistas. Neste trabalho, buscaremos analisar especialmente as Áreas de Proteção Ambiental (APAs), cuja legislação regulamenta a proteção de meios naturais frágeis e com grande biodiversidade, permitindo a permanência das populações nesses espaços preservados.

\section{As Áreas de Proteção Ambiental: a fragi-} lidade dos ecossistemas como base para a redefinição das formas de apropriação e uso dos territórios

Antes de apreciar-se as relações que se estabelecem entre as populações locais e as APAs, considera-se importante esclarecer alguns elementos específicos sobre esta forma de preservação.

A Lei Federal 6.902, de 27/4/81, estabelece que as Áreas de Proteção Ambiental são porções do território nacional de configuração e tamanho variáveis, submetidas a modalidades de manejos diversos, podendo compreender ampla gama de paisagens naturais e seminaturais, com características notáveis dotadas de atributos bióticos, estéticos ou culturais que exijam proteção para assegurar o bem-estar das populações humanas, conservar ou melhorar as condições ecológicas locais ou constituir-se em local de experimentação de novas técnicas e atitudes que permitam conciliar o uso da terra com a manutenção dos processos ecológicos essenciais. Para Schlittler, classicamente as APAs não são consideradas Unidades de Conservação, na concepção exata do termo, mas categorias adicionais de manejo em que os recursos podem sofrer "uso direto racional", através de um manejo sustentável.

Em seu Artigo $9^{\circ}$ esta Lei estabelece que para cada Área de Proteção Ambiental, dentro dos princípios constitucionais que regem o exercício do direito de propriedade, o Poder Executivo estabelecerá normas, limitando ou proibindo:

- a implantação e o funcionamento de indústrias potencialmente poluidoras, capazes de afetar mananciais de água;
- a realização de obras de terraplenagem e a abertura de canais, quando essas iniciativas importarem em sensível alteração das condições ecológicas locais;

- o exercício de atividades capazes de provocar uma acelerada erosão das terras e/ou um acentuado assoreamento das coleções hídricas;

- o exercício de atividades que ameacem extinguir na área protegida as espécies raras da biota regional.

As Áreas de Proteção Ambiental, enquanto Unidades de Conservação, podem ser delimitadas em terras de propriedade do governo ou mistas ou ainda em terras de particulares, necessitando apresentar, para serem adequadamente implantadas, um Plano de Manejo em co-gestão e participação da comunidade. Este manejo, no enfoque ecológico contemporâneo, parte dos conceitos de resiliência e capacidade de suporte.

$O$ conceito de resiliência implica na magnitude em que um determinado distúrbio, ou impacto, pode ser absorvido antes que um sistema ambiental se modifique. Para Begossi (1997), a resiliência está ligada à noção de ecossistemas com equilíbrios múltiplos e exige o conhecimento dos diversos limiares possíveis de reprodução de tais sistemas e o abandono da visão estrita de equilíbrio. Atualmente, "a análise científica dos ecossistemas naturais desvinculase cada vez mais da idéia de equilíbrio para incorporar as de variabilidade, de incerteza, de irreversibilidade das dinâmicas de transformação" (Weber et al., 1990). O conceito de resiliência, ou seja, a "capacidade de um sistema a responder a choques externos recompondo-se, reestruturando-se e chegando assim a um novo estado organizacional, questiona uma interpretação estática da noção de sustentabilidade" (Raynaut et al., 2000)

A capacidade de suporte fundamenta-se na noção de resiliência para introduzir as relações sociedade/natureza e pode ser definida como o tamanho máximo populacional de uma espécie que uma área pode suportar sem reduzir a sua habilidade de sustentar a mesma espécie no futuro. A capacidade de suporte depende do arsenal técnico que uma deter- 
minada comunidade é capaz de implementar em função de suas representações sobre a qualidade de vida ${ }^{4}$ (Roufhgarden, 1979, In: Ehelich, 1994, citado por Begossi, 1997).

Embora a noção de capacidade de suporte, quando utilizada isoladamente, apresente uma certa ambigüidade - sua definição podendo induzir a interpretações que levem à exclusão das populações residentes das áreas protegidas -, a conjugação desta noção com aquela de resiliência permite uma visão da relação sociedade/natureza distinta da visão que inspirou uma parte do discurso ambientalista e os principais instrumentos da legislação ambiental vigente que tenderam a privilegiar a natureza pensada como intocada, da ação predadora das populações (Diegues, 1998) ${ }^{5}$.

Observações oriundas de várias pesquisas empíricas mostram que as A.P.A.s, mesmo integrando o uso dos territórios protegidos pelas populações locais - o que significa um avanço em relação a uma visão estritamente preservacionista - geram, pelas limitações impostas às atividades produtivas no seu âmbito, restrições de uso inadequadas que não levam em conta os interesses reais e representações de natureza das comunidades locais.

\section{A Área de Proteção Ambiental de Guara- queçaba: as potencialidades regionais e a legislação ambiental}

O município de Guaraqueçaba, localizado no litoral norte do estado do Paraná, possui em seus limites uma área expressiva da Mata Atlântica ${ }^{6} \mathrm{e}$ tem a totalidade de sua superfície abrangida pela Área de Proteção Ambiental de Guaraqueçaba. Esta APA possui uma das maiores áreas representativas da Floresta Atlântica da região sul do Brasil e hoje reconhecida pela UNESCO como pertencente à Reserva da Biosfera da Mata Atlântica. Esta situação se deve ao fato de que esta porção do litoral brasileiro concentra ecossistemas de grande biodiversidade e relativa fragilidade em razão das suas características climáticas e geomorfológicas. Cabe salientar que a Floresta Atlântica contém mais de $50 \%$ da biodiversidade do planeta em $7 \%$ da superfície terrestre. A Mata Atlântica, como é denominada no Brasil, inclui as florestas estacionais semideciduais e originalmente foi a floresta com maior extensão latitudinal do planeta. Cobria uma faixa de $1.085 .000 \mathrm{~km}^{2}$, cerca de $11 \%$ do território nacional, e hoje está reduzida a cerca de $4 \%$ da cobertura original (DEAN, 1997). Estende-se pela face leste do território brasileiro, abrangendo uma grande variabilidade climáti-

${ }^{4}$ Inclui um $\mathrm{K}$ biofísico (máximo número de pessoas sustentado por uma dada tecnologia), e um $\mathrm{K}$ social (o K biofísico e a organização social da população, incluindo padrões de consumo e de comércio) Assim pode-se estabelecer a seguinte equação para se avaliar a capacidade de suporte de uma determinada área: o IPAT = I, impacto ambiental, $\mathrm{P}$ população, A atividade econômica per capita, $\mathrm{T}$ impacto (tecnológico) por unidade de atividade econômica, referido também com tecnologia.

${ }^{5}$ Como mostra Diegues, “... segundo essa filosofia, é imperioso salvar o que sobrou do mundo selvagem, devastado continuamente e de forma muitas vezes irreversível pelo homem. A concepção de áreas naturais protegidas como natureza selvagem parece ser um desses mitos. Nela parece operar-se uma simbiose entre o pensamento empírico-racional e o mitológico. Nesse conjunto de representações sobre o mundo natural e intocado, existem elementos claros que reportam ao pensamento empírico-racional, como a existência de funções ecológicas e sociais da natureza selvagem (o conceito de biodiversidade, por exemplo) dos processos ecológicos do ecossistema. De outro lado, existem nesse neomito elementos míticos claros que reportam à idéia do paraíso perdido, da beleza primitiva da natureza anterior à intervenção humana, da exuberância do mundo natural que leva o homem urbanizado a apreciar o belo, o harmonioso, a paz interior proveniente da admiração da paisagem intocada" (Diegues, 1998).

${ }^{6}$ O Decreto $n^{\circ} 750$, de 10/02/93, considera como sendo Mata Atlântica as formações florestais e ecossistemas associados inseridos no domínio Mata Atlântica, com as respectivas delimitações estabelecidas pelo Mapa de Vegetação do Brasil, IBGE, 1988: Floresta Ombrófila Densa Atlântica, Floresta Ombrófila Mista, Floresta Ombrófila Aberta, Floresta Estacional Semidecidual, Floresta Estacional Decidual, Manguezais, Restingas, Campos de altitude, Brejos interioranos e os enclaves florestais do Nordeste. 
ca, englobando desde climas temperados superúmidos no extremo sul até os tropicais úmido e semiárido de leste $\mathrm{e}$ nordeste, respectivamente, situando-se num relevo serrano da zona costeira. Nos vales e baixas encostas a floresta é mais densa que nas altas encostas, sendo que nos altos topos ocorrem campos de altitude. Ao sul ela se mescla com a floresta de Araucárias.

$\mathrm{Na}$ área de estudo, a Mata Atlântica está protegida por diversos instrumentos legais, como o Código Florestal e demais leis federais e estaduais sobre o uso do solo e das florestas. O Decreto Estadual $\mathrm{n}^{\circ}$ 5.040/89 dispõe sobre o Macrozoneamento da Região do Litoral do Paraná e das Unidades de Conservação. O Decreto Federal nº 87.222, de maio de 1982, criou a Estação Ecológica de Guaraqueçaba, com uma área de 13.638 hectares. Na APA de Guaraqueçaba ainda incidem espaços protegidos pela Lei Estadual $\mathrm{n}^{\circ} 7.919$, de 22/10/84, regulamentada pelo Decreto $n^{\circ} 5.308$, de 18/4/85, que criou a Área Especial de Interesse Turístico do Marumbi. O Decreto Federal $n^{\circ} 90.883$, de $31 / 10 / 85$, criou a Área de Proteção Ambiental de Guaraqueçaba, que abrange parte dos municípios de Guaraqueçaba, Antonina, Paranaguá e Campina Grande do Sul, perfazendo uma área de 314.400 hectares, dos quais sua maior parte no município de Guaraqueçaba. O Decreto Federal ${ }^{\circ} 91.888$, de 05/11/85, criou ainda a Área de Relevante Interesse Ecológico das Ilhas do Pinheiro e Pinheirinho, com uma área de 109 hectares. O Decreto Federal $\mathrm{n}^{\circ}$ 97.688, de 25/4/89, criou o Parque Nacional do Superaguii, com uma área de 21.400 hectares. Cabe salientar também a existência de uma Reserva Particular do Patrimônio Natural no município de Guaraqueçaba, a Reserva Natural Salto Morato (SEDU, 1990).

Na proteção e utilização deste ecossistema devem ser observados, segundo a legislação, os princípios relativos às funções socioambientais dos estabelecimentos agrícolas. O corte, a supressão e a exploração da vegetação dos ecossistemas atlânticos deverão ser feitos de maneira diferenciada, conforme se trate de vegetação primária ou secundária, neste caso levando-se em conta o seu estágio de regenera- ção. O corte ou supressão da vegetação são condicionados à compensação ambiental, na forma de destinação de área equivalente à extensão da área desmatada, com as mesmas características ecológicas e na mesma bacia hidrográfica, se possível na mesma microbacia hidrográfica. Nestes ecossistemas é livre a coleta de subprodutos florestais, tais como frutos, folhas ou sementes, bem como atividades de uso indireto, desde que não coloquem em risco as espécies da fauna e flora e normas legais de biosegurança.

\section{População, modos de uso e apropriação dos recursos naturais}

\section{A agricultura: origens e evolução histórica}

Em função desta significativa presença da Mata Atlântica e de outros ecossistemas com importante biodiversidade natural, o litoral do Paraná apresenta especificidades que influenciaram profundamente $o$ seu processo de ocupação agrícola. A reconstituição das principais etapas da evolução da agricultura, principal modo de uso dos recursos naturais na região, nos permite melhor visualizar estas especificidades.

O início da ocupação colonial da região litoral do Paraná pelos portugueses ocorre em meados do século XVI. A miscigenação com as populações indígenas presentes e, mais tarde, com populações negras, deu origem a uma formação social e a uma cultura original conhecida como caiçara (Diegues, 1994). A reconstituição da evolução dos sistemas agrários da região até o início do século XX revelou uma sociedade que constituiu sua base material a partir de um modo de exploração do meio baseado na apropriação direta dos recursos naturais, na transformação artesanal dos produtos florestais e agrícolas e em uma agricultura manual baseada no sistema de cultivo de queimadas com um período de pousio de longa duração, superior a 15 anos. As populações locais procediam, assim, à exploração dos ecossistemas locais através de práticas adaptadas de longa data ao meio natural e dispunham de uma grande autonomia alimentar e material em relação ao exterior. Tal situação não impediu, no entanto, que a so- 
ciedade local fosse marcada por um longo processo de diferenciação social. Este teve início nos primeiros tempos da colonização portuguesa, devido às atividades auríferas e à conseqüente apropriação, por uma parte dos agricultores locais, das terras melhor desservidas pela rede fluvial. Permitiu a esses agricultores darem início a uma longa fase de acumulação de capital e de meios de produção (Miguel, 1997). Por mais "tradicional" que fosse esta formação social, ela já incorporava tensões internas que antecipavam contradições e conflitos internos pela posse e uso dos recursos locais que emergiram posteriormente.

Até a metade do século XIX, a sociedade local era formada por homens livres e por escravos distribuídos em numerosos estabelecimentos agrícolas, em grande parte constituídos por pequenas unidades familiares. A abolição da escravidão, ao final deste século, foi o primeiro acontecimento gerador de uma aceleração das mudanças nesta sociedade agrária, iniciando um importante processo de reorganização social. As principais consequiências deste processo foram o desaparecimento dos grandes estabelecimentos agrícolas e uma reorientação das atividades e estratégias produtivas dos demais estabelecimentos. As primeiras décadas do século XX foram marcadas pelo desenvolvimento de um novo mercado para a produção local de banana a partir do crescimento da demanda por parte dos países do Prata - Argentina e Uruguai.

A abertura deste mercado ocasionou um efeito estruturante e dinamizante na sociedade agrária local, ainda fortemente marcada pela supressão da escravidão. Esta situação favoreceu o surgimento de uma nova estratificação social, estreitamente relacionada com o acesso à produção e à comercialização da banana. Assim, a grande maioria dos pequenos agricultores locais, cuja situação econômica e fundiária era de notória precariedade, foram obrigados a limitar suas atividades à produção de subsistência, sem obter uma maior inserção na economia de mercado. Somente uma pequena parte dos agricultores locais, por disporem de um nível de acumulação mais elevado em meios de produção, obtiveram êxito em implementar áreas de cultivo de banana.
Este período de transição teve consequiências demográficas bastante significativas para o litoral norte do Paraná pois, entre 1890 e 1910, a população da região duplicou. O significativo aumento populacional acarretou uma profunda modificação na paisagem agrária local em decorrência da expansão das áreas cultivadas e da redução das áreas de floresta. No entanto, a continuidade da expansão das áreas de cultivo foi, rapidamente, confrontada à ocupação da totalidade da área agrícola disponível nos vales e baixas encostas. Nessas condições, o aumento da superfície cultivada somente poderia ocorrer com a aceleração do ritmo de rotação das parcelas cultivadas e, portanto, em detrimento da duração do período de pousio que reduziu-se, progressivamente, para menos de seis anos para a maioria das parcelas agrícolas. Este processo foi responsável pela diminuição da fertilidade do solo das parcelas cultivadas (devido à menor acumulação de biomassa vegetal no decorrer do período de pousio) e pela perda de eficácia do pousio no controle das ervas invasoras. Consequientemente, os agricultores foram confrontados a uma importante diminuição dos rendimentos físicos da produção e da produtividade do trabalho (Miguel, 1997). Às consequiências desta crise agrícola acrescentaram-se aquelas decorrentes do término das exportações de banana para os países do Prata, no início dos anos 30 , devido à concorrência exercida pela produção da região litorânea de São Paulo. Por sua vez, o desenvolvimento da produção de mandioca e a sua transformação local em farinha para o mercado regional compensou apenas parcialmente o declínio do comércio da banana.

Concomitantemente às modificações da paisagem e dos sistemas naturais, esse período histórico foi marcado pela intensificação das transformações da sociedade local, iniciadas no final do século anterior com o desaparecimento do sistema escravocrata. Trazidas por importantes fluxos migratórios de amplitude nacional, novas populações, com tradições culturais diferentes (alemães, italianos, nordestinos, etc.) aportam no litoral norte do Paraná. As dinâmicas de diferenciação social reforçam os privilégios de uma parcela reduzida dos agricultores locais (os 
agricultores patronais) que puderam, assim, consolidar e expandir o controle sobre a produção e a comercialização dos produtos agrícolas e florestais. As décadas de 20 e 30 foram marcadas pelo fim do ciclo de prosperidade da banana e o aparecimento de uma grave crise na agricultura de queimada praticada pelos agricultores desta região. Os agricultores patronais, assim como parte dos comerciantes locais, por disporem dos meios materiais e econômicos para implementar modificações em seus sistemas de produção, puderam desenvolver novas atividades produtivas, em particular, a comercialização do palmito (Euterpe edulis). Inversamente, a maioria dos pequenos agricultores locais, além de estarem confrontados ao acesso limitado aos meios de produção e ao capital exigido para as transformações de seus sistemas de produção, foram igualmente atingidos pela crise no sistema de queimada e pela redução da demanda de mão-de-obra por parte dos agricultores patronais, sendo impelidos a adotar novas estratégias de sobrevivência. Pelas razões citadas, os pequenos agricultores foram levados a intensificar a extração de produtos agroflorestais (principalmente palmito), tornando-se ainda mais dependentes dos agricultores patronais e comerciantes, junto aos quais obtinham créditos, alimentação e medicamentos. Resultante disto é o abandono das culturas de subsistência em benefício da extração do palmito (Miguel e Zanoni, 1998a, 1998b). Em outros casos, ocorreu a migração de pequenos agricultores para as vilas situadas à beira da baía, onde se tornaram pescadores, ou ainda para os centros urbanos do litoral (Rougeulle, 1993).

A partir dos anos 50, inicia-se no litoral norte do Paraná um período de decréscimo populacional, com um fluxo migratório direcionado para a cidade de Paranaguá, cujo porto iniciava uma fase de crescimento rápido (Godoy, 1998), com possibilidades de absorção de mão-de-obra. O final dos anos 60 foi marcado por novas e profundas transformações na realidade agrária local, em grande parte conseqüência de uma série de intervenções dos poderes públicos. A implementação, por parte do governo federal, de uma política de incentivos fiscais visando o desenvolvimento de atividades agroflorestais estimu- lou uma série de empresas a constituírem grandes latifúndios no litoral paranaense, apropriando-se de terras devolutas ou pertencentes aos agricultores locais para desenvolverem novas atividades econômicas: extração da madeira e do palmito, cultivo do café, criação de bovinos e búfalos (Miguel, 1997). Com o intuito de consolidar este processo, o poder público paranaense realizou uma série de infra-estruturas rodoviárias visando facilitar o acesso à região, inaugurando nos anos 60 o grande eixo ligando Curitiba a Paranaguá e, nos anos 70, uma estrada de terra entre Guaraqueçaba e Antonina. Estas novas infra-estruturas viárias tiveram um efeito determinante na reorganização da circulação de mercadorias e de pessoas no espaço litorâneo e nas ligações destes com outras regiões. $\mathrm{O}$ modal rodoviário passou a, progressivamente, monopolizar o transporte que, até então, tinha sido exclusivamente fluvial e marítimo, modificando consideravelmente o padrão de relacionamento da sociedade local com seu espaço: os rios e os vales foram gradativamente perdendo seu papel estruturante, enquanto a estrada passou a exercer um efeito aglutinador sobre as atividades econômicas e sobre a presença humana.

A chegada de novos tipos de produtores e investidores, obedecendo a outras lógicas sociais e econômicas, e a maior integração da região com as regiões vizinhas, modificaram radicalmente as bases de funcionamento da sociedade local e as condições de seu relacionamento com o espaço e os recursos naturais. Em síntese, e não abstraindo a complexidade dos processos que ocorreram neste período, podemos dizer que esta estapa da história agrária do litoral norte do Paraná, do final dos anos 60 até o início dos anos 80, caracterizou-se por três grandes tendências estreitamente articuladas (Raynaut et al., 2000):

- a aparição de novos atores, alheios à sociedade local, cujas estratégias de acumulação econômica estavam mais ligadas à captação da renda fundiária (aproveitando subsídios públicos, contando com a valorização da terra) do que ao exercício efetivo de atividades produtivas; 
- o papel dominante do extrativismo (principalmente do palmito) como forma de exploração dos recursos naturais;

- a marginalização econômica de uma grande maioria dos agricultores locais.

Esta nova conjuntura ocasionou a eclosão de violentos conflitos entre os produtores e investidores recém-chegados e os agricultores locais. A história agrária do litoral norte do Paraná registra, assim, novas alterações das formas de exploração dos recursos naturais, da estrutura da paisagem e da organização da sociedade local. Verifica-se um processo de degradação dos ecossistemas a um nível, até então, raramente alcançado no litoral norte: exploração excessiva dos palmitais nativos e desmatamento de vastas áreas florestais para a implantação de pastagens para a criação extensiva de búfalos (Miguel e Zanoni, 1998a, 1998b).

Foi justamente com o intuito de inverter esse processo de degradação dos ecossistemas florestais, em decorrência da expansão das atividades realizadas pelos grandes proprietários, que os poderes públicos elaboraram e implantaram uma política de proteção ambiental específica para esta região, descrita em páginas precedentes. Esta política de proteção ambiental é estruturada a partir da promulgação de uma série de dispositivos regulamentando as práticas agrícolas e florestais. Do mesmo modo, a exploração dos recursos florestais, especialmente do palmito, foi contemplada com uma série de regulamentações.

\section{Agricultores familiares e populações tradicionais}

Antes de proceder-se à análise dos impactos que a criação da APA teve sobre as populações locais, é importante entender esta conceituação que adjetiva tais populações como tradicionais. $\mathrm{O}$ peso teórico do conceito, irremediavelmente ligado, na literatura dos estudos rurais e agrícolas, ao pensamento dualista, impõe a necessidade de retomá-lo, salientando seu significado no caso estudado, até porque pode suscitar interpretações que são contrárias às conclusões preliminares aqui constatadas.

$\mathrm{Na}$ legislação que criou as APAs e, em especial, a APA de Guaraqueçaba, os habitantes locais, definidos como populações tradicionais, deveriam ter suas condições de vida e seus modos de acesso e uso aos recursos naturais protegidos, da mesma forma que o meio natural que se estava preservando: "a Área de Proteção Ambiental de Guaraqueçaba é uma das últimas áreas representativas da Floresta Atlântica, reunindo espécies ameaçadas de extinção, sítios arqueológicos, complexo estuarino da baía de Paranaguá e comunidades tradicionais localizadas da região" (Decreto Federal n 90.883, de 31/10/85).

Pensá-los como populações tradicionais, como o fizeram vários cientistas naturalistas envolvidos com a criação de APAs, foi uma das formas de integrá-los à perspectiva de preservação, posicionandose num debate em curso onde a manutenção de populações em unidades de proteção da natureza não obteve facilmente adesões de ambientalistas. A idéia originária de que estas populações constituem empecilhos aos objetivos destas unidades, já que portadoras de patrimônios selvagens - wilderness (Diegues, 1998), passou a incorporar o vetor desta permanência no maior ou menor grau de harmonia das suas relações com a natureza (Brito, 1998). O conceito de populações tradicionais teve o mérito de afirmar a necessidade de criar as condições de permanência e desenvolvimento dos habitantes locais e o fez resgatando-os como aqueles que construíram o espaço com seus modos de vida bastante próximos e dependentes do meio natural local. Constitui-se numa visão mais aberta a outros requisitos que aqueles de ordem estritamente biológica, quando comparados aos que nortearam a criação de outros espaços de preservação, como os parques naturais destinados à exclusiva preservação da flora e da fauna, ilustrando a concepção de natureza intocada (Diegues, 1998).

No Brasil, além dos numerosos estudos sobre as sociedades amazônicas, boa parte da literatura sobre populações tradicionais se construiu na análise de populações caiçaras - habitantes de áreas litorâneas que combinavam pesca com extrativismo e 
agricultura. Embora possa ser problemático denominar de caiçaras os habitantes das áreas rurais interioranas dos municípios litorâneos, usou-se normalmente a mesma conceituação de tradicionais para designar os camponeses/coletores das comunidades rurais locais. Uma versão clássica do conceito de populações ou comunidades tradicionais, calcada em estudos empíricos, aponta para as seguintes características:

- dependência e até simbiose com a natureza, os ciclos naturais e os recursos naturais renováveis a partir do qual se constrói um "modo de vida"; - conhecimento aprofundado da natureza e de seus ciclos que se reflete na elaboração de estratégias de uso e de manejo dos recursos naturais. Este conhecimento é transferido oralmente de geração em geração;

- noção de "território" ou espaço onde o grupo social se reproduz econômica e socialmente;

- moradia e ocupação desse "território" por várias gerações, ainda que alguns membros individuais possam ter se deslocado para os centros urbanos e voltado para a terra de seus antepassados;

- importância das atividades de subsistência, ainda que a produção de mercadorias possa estar mais ou menos desenvolvida, o que implica uma relação com o mercado;

- reduzida acumulação de capital;

- importância dada à unidade familiar, doméstica ou comunal e às relações de parentesco ou compadrio para o exercício das atividades econômicas, sociais e culturais;

- importância das simbologias, mitos e rituais associados à caça, à pesca e atividades extrativistas;

- tecnologia utilizada relativamente simples, de impacto limitado sobre o meio ambiente, reduzida divisão técnica e social do trabalho, sobressaindo a transformação artesanal, onde o produtor (e sua família) domina o processo de trabalho até o produto final;

- pouca expressão em termos de poder político; - autoidentificação ou identificação pelos outros de pertencer a uma cultura distinta das demais (Diegues e Nogara, 1994).

Esta caracterização certamente descreve aspectos importantes dos modos de vida de parte das comunidades de habitantes das APAs. Aponta para muitas especificidades de populações definidas, nos estudos rurais, como comunidades camponesas. Tratá-las como tradicionais pode ter o mérito de mostrar sua antigüidade como povoadoras da região onde vivem, além do fato de respaldar sua permanência nos espaços de proteção ambiental. No entanto, tal concepção pode gerar ambigüidades que podem obscurecer ao invés de facilitar a compreensão das dinâmicas históricas reais que produzem, reproduzem e transformam tais modos de vida. $\mathrm{O}$ próprio conceito de tradicional, como adjetivo de populações moradoras de uma dada região, pode implicar numa tendência para uniformizar pessoas, grupos e comunidades extremamente heterogêneas e pode dificultar a apreensão de sua historicidade. No caso do litoral norte do Paraná, pode-se constatar que, anteriormente ao momento da criação da APA, identificou-se a existência de um processo de diferenciação social em curso, ligado a uma história de distintas formas e possibilidades de acesso à terra e a ciclos de integração ao mercado e de decadência (Miguel, 1997). Além disto, ao longo de sua história posterior, os modos de vida das populações locais foram se transformando em função das novas restrições impostas pela APA e da ausência de uma política de desenvolvimento rural que contemplasse outras possibilidades para os agricultores e moradores rurais.

Os responsáveis pela legislação ambiental e algumas ONGs ambientalistas atuantes no litoral norte do Paraná tendem a utilizar este conceito neste sentido, ou seja, pelo viés de uma fusão implícita entre homens naturais em uma natureza naturaliza$d a$. Isto implica em cristalizar populações com uma história de diversos usos de seu meio num tempo e num uso idealizado, a-histórico, a ser preservado. Os atores sociais reais, que não se restringem a esta categorização, são considerados implicitamente como predadores da natureza, os antinatureza a serem controlados pela vigilância científica, pela legislação e não como exceção, mas como derivação necessária desta postura - e pela polícia.

Obviamente não se pode imputar uma relação de causa e efeito a uma teoria e aos usos sociais diretos e indiretos que se fazem dela, mas pensar uma 
conceituação mais adequada à realidade simultaneamente em crise e transformação, como a identificada na litoral norte do Paraná, é uma tarefa importante. No momento, pensa-se em agricultores familiares e moradores rurais que diversificam suas estratégias de reprodução para fazer face a uma situação duplamente de marginalização e de bloqueio às suas atividades: a lei ambiental, com seus impactos sobre a agricultura, extrativismo e pesca, e, no caso dos agricultores, compartilhando o destino de outros pequenos agricultores familiares no país, com a ausência de políticas de desenvolvimento agrícola e rural que criem condições para suas atividades produtivas e para sua vida no meio rural com acesso a bens e serviços que lhes seriam fundamentais.

\section{Impactos da criação da APA sobre as} práticas técnicas dos agricultores familiares

Os trabalhos de Zanoni e Miguel (1995, 1998a e 1998b) e Miguel (1997) mostraram que a implementação da política de proteção ambiental e a regulamentação da APA no litoral norte do Paraná ocasionaram uma série de restrições ao modo de exploração do meio adotado pelas populações tradicionais desta região. As principais restrições as atividades agrícolas podem ser agrupadas em três grupos:

\section{- Autorizações obrigatórias para desma-} tamento e roçada

Antes de qualquer desmatamento ou roçada, o agricultor é obrigado a solicitar uma autorização ao IBAMA e ao IAP. A demora dos trâmites administrativos e os constantes atrasos na expedição das autorizações ocasionam transtornos ao calendário agrícola e, principalmente, atrasos no preparo das parcelas, podendo as autorizações demorarem algumas semanas ou mesmo vários meses. Ora, no sistema de plantio sobre queimada, qualquer alteração no período de roçada e, conseqüentemente, de queimada, ocasiona um aumento dos riscos: quanto mais próximo ao período estival ocorrer a roçada, maiores serão as probabilidades de chuvas após a derrubada da vegetação, o que pode conduzir a uma secagem imperfeita da biomassa vegetal e à impossibilidade de efetuar a queimada e o plantio.

- Proibição de desmatamento nas margens dos cursos d'água

A banana e o milho são as duas culturas mais atingidas por essa medida que, por proibir o corte da vegetação natural ao longo dos cursos d'água, impede a expansão da área cultivada com a incorporação de novas parcelas. Ora, os sistemas de cultivo da banana e do milho utilizados nesta região se mostram bem adaptados às margens de cursos d'água: a cobertura do solo limita a erosão e a reprodução da fertilidade é assegurada pelos depósitos aluvionais trazidos pelas enchentes.

- Restrição ao desmatamento nas encostas e nos terrenos baixos

Esta medida tem um impacto sobre as culturas de subsistência - anuais e bienais - (milho, arroz, feijão, mandioca) e sobres aquelas destinadas à venda ou à alimentação animal. Proíbe-se os agricultores de efetuar um novo plantio em parcelas recobertas por vegetação com idade estimada em mais de sete anos para os terrenos planos (vegetação arbórea) e superiores a quatro anos para as encostas (vegetação arbustiva). Essa restrição obriga os agricultores a reduzirem o período de pousio no sistema de cultivo de queimada, acarretando, conseqüentemente, uma diminuição do volume de biomassa vegetal, único ou principal fertilizante do solo, reduzindo-se assim a sua fertilidade e a eficácia do controle das ervas adventícias.

Além das restrições à agricultura, a legislação é particularmente restritiva quanto ao uso dos recursos florestais. A legislação referente à atividade de extração e beneficiamento do palmito, anterior à legislação ambiental específica ao litoral norte do Paraná, não somente reforçou a restrição de direito de corte dessa espécie aos grandes proprietários como fortaleceu o monopólio das indústrias de conservas para a transformação e comercialização. Assim, tanto a extração como o beneficiamento do palmito reali- 
zados pelos agricultores locais permaneceram ilegais, sendo severamente reprimidos pelos órgãos ambientais. Esta situação de clandestinidade, acrescida de uma crescente demanda tanto no mercado nacional como internacional por este produto, tem como conseqüência uma crescente intensificação da exploração desta palmeira. Essa transgressão a legislação é feita de comum acordo entre aqueles que efetuam a extração e os que possuem as indústrias de conservas. No entanto, para cobrir os custos com "propinas", os proprietários das indústrias subtraem esses gastos da remuneração paga aos palmiteiros que, por sua vez, compensam o prejuízo com o aumento dos volumes de palmito extraídos da floresta.

Como esta regulamentação de uso acaba acarretando uma superexploração dos estoques de palmito, registra-se o paradoxo de que a legislação tem o efeito contrário de seus objetivos: não somente o recurso palmito tende a se rarificar, como também ocorre um empobrecimento da fauna que se alimenta dos grãos desta palmeira e que, ao mesmo tempo, contribui para a sua disseminação. Para o palmiteiro - que é um agricultor ou ex-agricultor que vive no meio rural do município -, registra-se o aumento na penosidade do trabalho, em função das distâncias maiores a percorrer na busca de áreas florestais com maior densidade de palmito nativo. Além disto, é uma atividade de risco para o coletor por ser considerada clandestina, embora as firmas compradoras possam transformar e vender o produto legalmente $\mathrm{e}$ sem sofrer os contrangimentos da situação de ilegalidade vivenciada pelos que o extraem: "em suma, enquanto o corte do palmito é clandestino e a mãode-obra que o coleta é igualmente clandestina, sua venda clandestina é legal" (Zanoni e Miguel, 1995).

Também as atividades de caça e de extração de outras essências florestais são regulamentadas pela legislação vigente. A criação da Área de Proteção Ambiental ampliou os efeitos do código de caça, que, por si só, já proíbe qualquer atividade de caça. Essa lei amplia as restrições para as populações locais, para as quais a caça fornece uma parte essencial da ração protéica, principalmente para os mais desfavorecidos. A caça clandestina é cada vez mais freqüente e, por conseguinte, praticada sem a eficiên- cia das práticas tradicionais de gestão dos estoques: face a severas punições dos atos de "flagrante delito", os caçadores clandestinos são incentivados a capturar qualquer tipo de caça, sem distinção de idade, sexo ou espécie. A proibição total dessa atividade, provoca, paradoxalmente, o desaparecimento efetivo de algumas espécies endêmicas da floresta tropical atlântica. $\mathrm{O}$ mesmo ocorre com essências florestais que fornecem matéria-prima ao artesanato local (fabricação de canoas, de cordas, redes de pesca, cestos, etc.). Novamente, as restrições de uso dos recursos - no caso os recursos florestais - acabam por acarretar impactos negativos sobre o próprio ambiente que se buscava preservar. $O$ desconhecimento de saberes locais dos agricultores e habitantes e a imposição de um saber científico que lhes é estranho produzem um descompasso entre as necessidades reais de proteção e os limites de uso possíveis de serem alcançados.

\section{As estratégias dos agricultores diante das restrições às suas atividades}

Diante destas restrições, os agricultores locais têm adotado diferentes estratégias, algumas específicas às áreas de proteção ambiental, outras típicas de agricultores familiares em geral.

\section{- Estratégias adotadas em relação às práticas agrícolas}

O desmatamento clandestino constitui uma estratégia em resposta a diferentes restrições. Para compensar os danos provocados pela obrigatoriedade de autorização prévia de desmatamento, ou pela interdição de cultivo nas margens dos cursos d'água ou nas encostas das montanhas, o desmatamento clandestino nas parcelas agrícolas se configura como uma importante estratégia para permitir a manutenção da superfície agrícola útil (SAU) dos estabelecimentos. Frequientemente, as parcelas desmatadas clandestinamente situam-se na mata secundária e não dispõem de boas condições de plantio (difícil acesso, grande declividade, solos frágeis e pouco desenvolvidos). Contrariando os objetivos de proteção da na- 
conceituação mais adequada à realidade simultaneamente em crise e transformação, como a identificada na litoral norte do Paraná, é uma tarefa importante. No momento, pensa-se em agricultores familiares e moradores rurais que diversificam suas estratégias de reprodução para fazer face a uma situação duplamente de marginalização e de bloqueio às suas atividades: a lei ambiental, com seus impactos sobre a agricultura, extrativismo e pesca, e, no caso dos agricultores, compartilhando o destino de outros pequenos agricultores familiares no país, com a ausência de políticas de desenvolvimento agrícola e rural que criem condições para suas atividades produtivas $\mathrm{e}$ para sua vida no meio rural com acesso a bens e serviços que lhes seriam fundamentais.

\section{Impactos da criação da APA sobre as práticas técnicas dos agricultores familiares}

Os trabalhos de Zanoni e Miguel (1995, 1998a e 1998b) e Miguel (1997) mostraram que a implementação da política de proteção ambiental e a regulamentação da APA no litoral norte do Paraná ocasionaram uma série de restrições ao modo de exploração do meio adotado pelas populações tradicionais desta região. As principais restrições as atividades agrícolas podem ser agrupadas em três grupos:

- Autorizações obrigatórias para desmatamento e roçada

Antes de qualquer desmatamento ou roçada, o agricultor é obrigado a solicitar uma autorização ao IBAMA e ao IAP. A demora dos trâmites administrativos e os constantes atrasos na expedição das autorizações ocasionam transtornos ao calendário agrícola e, principalmente, atrasos no preparo das parcelas, podendo as autorizações demorarem algumas semanas ou mesmo vários meses. Ora, no sistema de plantio sobre queimada, qualquer alteração no período de roçada e, conseqüentemente, de queimada, ocasiona um aumento dos riscos: quanto mais próximo ao período estival ocorrer a roçada, maiores serão as probabilidades de chuvas após a derrubada da vegetação, o que pode conduzir a uma secagem imperfeita da biomassa vegetal e à impossibilidade de efetuar a queimada e o plantio.

- Proibição de desmatamento nas margens dos cursos d'água

A banana e o milho são as duas culturas mais atingidas por essa medida que, por proibir o corte da vegetação natural ao longo dos cursos d'água, impede a expansão da área cultivada com a incorporação de novas parcelas. Ora, os sistemas de cultivo da banana e do milho utilizados nesta região se mostram bem adaptados às margens de cursos d'água: a cobertura do solo limita a erosão e a reprodução da fertilidade é assegurada pelos depósitos aluvionais trazidos pelas enchentes.

- Restrição ao desmatamento nas encostas e nos terrenos baixos

Esta medida tem um impacto sobre as culturas de subsistência - anuais e bienais - (milho, arroz, feijão, mandioca) e sobres aquelas destinadas à venda ou à alimentação animal. Proíbe-se os agricultores de efetuar um novo plantio em parcelas recobertas por vegetação com idade estimada em mais de sete anos para os terrenos planos (vegetação arbórea) e superiores a quatro anos para as encostas (vegetação arbustiva). Essa restrição obriga os agricultores a reduzirem o período de pousio no sistema de cultivo de queimada, acarretando, conseqüentemente, uma diminuição do volume de biomassa vegetal, único ou principal fertilizante do solo, reduzindo-se assim a sua fertilidade e a eficácia do controle das ervas adventícias.

Além das restrições à agricultura, a legislação é particularmente restritiva quanto ao uso dos recursos florestais. A legislação referente à atividade de extração e beneficiamento do palmito, anterior à legislação ambiental específica ao litoral norte do Paraná, não somente reforçou a restrição de direito de corte dessa espécie aos grandes proprietários como fortaleceu o monopólio das indústrias de conservas para a transformação e comercialização. Assim, tanto a extração como o beneficiamento do palmito reali- 
zados pelos agricultores locais permaneceram ilegais, sendo severamente reprimidos pelos órgãos ambientais. Esta situação de clandestinidade, acrescida de uma crescente demanda tanto no mercado nacional como internacional por este produto, tem como conseqüência uma crescente intensificação da exploração desta palmeira. Essa transgressão a legislação é feita de comum acordo entre aqueles que efetuam a extração e os que possuem as indústrias de conservas. No entanto, para cobrir os custos com "propinas", os proprietários das indústrias subtraem esses gastos da remuneração paga aos palmiteiros que, por sua vez, compensam o prejuízo com o aumento dos volumes de palmito extraídos da floresta.

Como esta regulamentação de uso acaba acarretando uma superexploração dos estoques de palmito, registra-se o paradoxo de que a legislação tem o efeito contrário de seus objetivos: não somente o recurso palmito tende a se rarificar, como também ocorre um empobrecimento da fauna que se alimenta dos grãos desta palmeira e que, ao mesmo tempo, contribui para a sua disseminação. Para o palmiteiro - que é um agricultor ou ex-agricultor que vive no meio rural do município -, registra-se o aumento na penosidade do trabalho, em função das distâncias maiores a percorrer na busca de áreas florestais com maior densidade de palmito nativo. Além disto, é uma atividade de risco para o coletor por ser considerada clandestina, embora as firmas compradoras possam transformar e vender o produto legalmente $\mathrm{e}$ sem sofrer os contrangimentos da situação de ilegalidade vivenciada pelos que o extraem: "em suma, enquanto o corte do palmito é clandestino e a mãode-obra que o coleta é igualmente clandestina, sua venda clandestina é legal" (Zanoni e Miguel, 1995).

Também as atividades de caça e de extração de outras essências florestais são regulamentadas pela legislação vigente. A criação da Área de Proteção Ambiental ampliou os efeitos do código de caça, que, por si só, já proíbe qualquer atividade de caça. Essa lei amplia as restrições para as populações locais, para as quais a caça fornece uma parte essencial da ração protéica, principalmente para os mais desfavorecidos. A caça clandestina é cada vez mais freqüente e, por conseguinte, praticada sem a eficiên- cia das práticas tradicionais de gestão dos estoques: face a severas punições dos atos de "flagrante delito", os caçadores clandestinos são incentivados a capturar qualquer tipo de caça, sem distinção de idade, sexo ou espécie. A proibição total dessa atividade, provoca, paradoxalmente, o desaparecimento efetivo de algumas espécies endêmicas da floresta tropical atlântica. $\mathrm{O}$ mesmo ocorre com essências florestais que fornecem matéria-prima ao artesanato local (fabricação de canoas, de cordas, redes de pesca, cestos, etc.). Novamente, as restrições de uso dos recursos - no caso os recursos florestais - acabam por acarretar impactos negativos sobre o próprio ambiente que se buscava preservar. $\mathrm{O}$ desconhecimento de saberes locais dos agricultores e habitantes e a imposição de um saber científico que lhes é estranho produzem um descompasso entre as necessidades reais de proteção e os limites de uso possíveis de serem alcançados.

\section{As estratégias dos agricultores diante das restrições às suas atividades}

Diante destas restrições, os agricultores locais têm adotado diferentes estratégias, algumas específicas às áreas de proteção ambiental, outras típicas de agricultores familiares em geral.

\section{- Estratégias adotadas em relação às práticas agrícolas}

O desmatamento clandestino constitui uma estratégia em resposta a diferentes restrições. Para compensar os danos provocados pela obrigatoriedade de autorização prévia de desmatamento, ou pela interdição de cultivo nas margens dos cursos d'água ou nas encostas das montanhas, o desmatamento clandestino nas parcelas agrícolas se configura como uma importante estratégia para permitir a manutenção da superfície agrícola útil (SAU) dos estabelecimentos. Frequientemente, as parcelas desmatadas clandestinamente situam-se na mata secundária e não dispõem de boas condições de plantio (difícil acesso, grande declividade, solos frágeis e pouco desenvolvidos). Contrariando os objetivos de proteção da na- 
tureza, esta restrição acarreta a aceleração do processo de degradação do ecossistema florestal. No que diz respeito ao estabelecimento agrícola, o cultivo de modo clandestino dessas parcelas - freqüentemente distantes dos estabelecimentos - interfere na gestão da mão-de-obra, pois os deslocamentos se traduzem por um investimento complementar em trabalho e, conseqüentemente, em uma concorrência com as outras atividades agrícolas, contribuindo também para a desorganização do calendário agrícola.

Constata-se, portanto, que uma única restrição referente ao desmatamento pode desencadear diferentes estratégias. Tal restrição se traduz por uma queda dos rendimentos agrícolas (em decorrência da queda da fertilidade das parcelas) e pelo aumento das necessidades em tempo de capina, determinando, em parte, uma queda da produtividade do trabalho. Além disso, quando se trata de culturas destinadas ao autoconsumo, essa restrição tem como conseqüência uma perda da autonomia alimentar das populações locais. Face a tal restrição, várias situações foram identificadas. Para os agricultores que aceitam essas regras, cultivando apenas as parcelas em conformidade com as determinações legais, duas alternativas são possíveis. Alguns adotam uma estratégia que consiste na utilização de herbicidas para o controle das ervas adventíceas, mas, neste caso, arcam com um aumento dos custos de produção. Outros se resignam ao aumento do tempo de trabalho com a capina manual, o que se traduz por uma queda da produtividade do trabalho.

No caso de não concordarem em submeter-se à legislação, os agricultores adotam a estratégia de transgressão descrita anteriormente, cultivando clandestinamente parcelas isoladas, e que, portanto, fo- gem ao controle dos organismos de proteção ambiental.

O aumento dos custos de produção e do tempo de trabalho, a queda da produtividade do trabalho e a perda da autonomia alimentar, são fatores que podem comprometer a reprodução social destes agricultores familiares. No que se refere à proteção da natureza, os efeitos perversos dessa legislação são, respectivamente, a poluição dos solos e das águas, a redução da fauna aquática e terrestre, a depredação dos povoamentos naturais de palmito, o desmatamento e a erosão dos solos, efeitos que contrariam os objetivos dessa legislação.

\section{- Estratégias adotadas pelos agricultores locais em relação ao palmito}

As particularidades envolvendo a atividade de extração e beneficiamento clandestino do palmito permitiram a formação, no litoral norte do Paraná, de uma intrincada e complexa rede social envolvendo a família, a parentela e a comunidade em geral. Essa rede, ao mesmo tempo que recria solidariedades, deu origem a novas hieraquias de poder em nível local e mesmo regional. As atividades de extração e beneficiamento do palmito são, para significativo segmento dos agricultores familiares do litoral norte do Paraná, um importante e incontornável meio de assegurar a reprodução familiar no meio rural ${ }^{7}$. Envolvem freqüentemente mais de um membro de cada família nuclear, além de integrar membros da família extensa - como afirmou um agricultor local, "nada melhor do que contar com quem a gente confia para fazer uma atividade que é proibida".

Cada comunidade possui o seu "intermediário", ou seja, aquele indivíduo que repassa o palmito in

\footnotetext{
${ }^{7}$ Em 1992, aproximadamente 2/3 dos estabelecimentos agrícolas do litoral norte do Paraná apresentavam a extração e/ou beneficiamento clandestino do palmito como uma atividade não agrícola (Miguel, 1997).

${ }^{8}$ Vários dos agricultores entrevistados, quando adquiriam confiança para falar das atividades de extração, mostravam esta divisão do trabalho no seio das famílias: os mais velhos não conseguem mais se dedicar à extração porque as distâncias são longas, mas alguns ainda vão com os filhos; os jovens se encarregam da maior parte da extração e mesmo crianças acompanham os pais para ajudar nas atividades de identificação e amarro dos feixes; as mulheres raramente se envolvem - só quando a força de trabalho familiar é escassa e sua ajuda é fundamental. Alguns agricultores deixaram completamente a atividade mas liberam os filhos para a coleta - uma agricultora disse que duas vezes por semana seus filhos vão para a extração e, nos demais dias, cuidam da agricultura.
} 
natura para os compradores das indústrias de conservas (que recebem localmente o sugestivo apelido de "gatos"). O "intermediário" tem como função acionar os palmiteiros quando há demanda, lidar com os esquemas de segurança da coleta, inclusive encarregando-se de neutralizar, em nível local, a ação dos policiais e fiscais dos órgãos ambientais. Este intermediário pode ou não ser um agricultor mais bem posicionado em termos econômicos na comunidade: sua notabilidade pode ser apenas social, como por exemplo, no caso de pertencer a uma das famílias de agricultores mais antigas ou mais numerosa. Se solidariedades antigas são reforçadas e novas são criadas, os conflitos pré-existentes são exarcebados e rivalidades recentes também se gestam neste processo. Se há ocorrência de casos de agricultores locais denunciando outros agricultores envolvidos com as atividades de extração e beneficiamento clandestino, raramente tal fato ocorre entre os membros de uma mesma rede. Em geral, constata-se o predomínio de uma "lei de silêncio" que resguarda essas atividades e mantém o sentido de comunidade como espaço de colaboração.

\section{- Estratégias ligadas à pluriatividade}

As atividades não agrícolas sempre tiveram uma grande importância para as populações tradicionais do litoral norte do Paraná. A sociedade agrária local, historicamente com fraca inserção no mercado regional, sempre buscou assegurar, com a transformação artesanal dos produtos agrícolas e florestais locais, grande parte de suas necessidades materiais. A esta situação, cabe acrescentar a ocorrência de um longo processo de crise das atividades agrícolas vivenciado pelas populações tradicionais locais a partir dos anos 1920-30. Entre as atividades não agrícolas cabe ressaltar, pela relevância adquirida nos últimos anos, a extração e transformação do palmito, a produção de farinha de mandioca, o artesanato e o assalariamento. As restrições impostas pela legislação ambiental, por limitarem o acesso às atividades agrícolas e por não proporcionarem alternativas de desenvolvimento rural, incentivaram as populações locais a desenvolver outras atividades.
As estratégias de pluriatividade identificadas no litoral norte do Paraná são bastante diferenciadas. No que se refere aos pequenos agricultores locais, em avançado processo de exclusão social, constatou-se a adoção de atividades fortemente ligadas ao extrativismo e à transformação clandestina de produtos florestais (em especial do palmito). Com efeito, as atividades de extração e transformação de produtos florestais, além de exigirem reduzidos investimentos em capital, são dificilmente controláveis pelos órgãos fiscalizadores, a produção é facilmente comercializável e proporciona uma elevada remuneração. Entre os agricultores patronais, identificouse o desenvolvimento de atividades não agrícolas ligadas à transformação de alguns produtos agrícolas locais como a produção de balas e passas de banana e de farinha de mandioca. Apesar de exigirem investimentos relativamente elevados (tanto em instalações como em maquinário), estas atividades apresentam conformidade com a legislação ambiental em vigor e, pelas particularidades e características dos produtos (artesanais e com qualidade diferenciada), proporcionam uma adequada remuneração aos agricultores. Por fim, cabe salientar o surgimento, mais recentemente, de novas atividades ligadas ao lazer e ao turismo de cunho ecológico (hospedagem, alimentação, artesanato tradicional, etc.). O desenvolvimento destas atividades pode ser imputado, de maneira indireta, à execução da política ambiental nesta região.

Apesar da crescente importância que estas atividades não agrícolas têm adquirido nos últimos anos e de um inquestionável potencial de desenvolvimento, elas tendem a beneficiar grupos restritos da população local. Com efeito, as atividades ligadas ao lazer e ao turismo exigem um nível de capacitação da mão-de-obra e uma disponibilidade em capital bastante superiores aos encontrados, atualmente, entre a maioria dos habitantes do litoral norte do Paraná.

Assim como em outras regiões do país e do mundo, a pluriatividade pode configurar uma importante fonte de renda e emprego para os habitantes desta região. As importantes carências ressentidas no setor da prestação de serviços e a perspectiva 
de uma gestão ambiental com atribuição de funções e responsabilidades à comunidade podem ocasionar novas possibilidades de renda e emprego para os agricultores e para os membros de suas famílias. Consolidam-se, assim, estratégias de complementação da renda renda agrícola e de criação de empregos para mulheres e jovens.

\section{Conclusões}

A análise da política de proteção ambiental colocada em prática no litoral norte do Paraná permitiu chegar a algumas conclusões. Se por um lado essa política ambiental acarretou uma certa desaceleração do processo de degradação dos recursos naturais, por outro lado ela se mostrou incapaz de reverter o quadro de pauperismo histórico vivido por grande parte das populações locais. Na medida em que esta política ambiental foi elaborada sem considerar o modo de exploração do meio tradicionalmente praticado por estas populações, baseados essencialmente na apropriação direta dos recursos naturais, ela induziu à adoção, por parte destas populações, de práticas agrícolas e agroflorestais que, paradoxalmente, contribuíram ainda mais para a degradação desses ecossistemas. Igualmente, a maioria dos agricultores locais se tornaram "reféns" de uma situação marcada por uma profunda desigualdade: interdição de acesso aos recursos fundiários e florestais de um lado, e imposição de uma política ambiental que não soube identificar os reais responsáveis pela degradação dos ecossistemas locais, por outro lado.

A política de proteção ambiental implementada no litoral norte do Paraná, criada com o intuito de resguardar os ecossistemas de floresta tropical atlântica e a cultura das populações tradicionais locais, não alcançou os resultados esperados. Primeiramente, pode-se constatar a não adesão de grande parte da população local à quase totalidade das regras fixadas. Com efeito, o dispositivo legal instituído por esta política ambiental desconsiderou os problemas enfrentados por estas populações para garantir a sua segurança alimentar e assegurar sua reprodução social. Igualmente, constatou-se a impossibilidade da aplicação desta política ambiental dentro de uma conjuntura onde os poderes públicos se mostram incapazes de fazer respeitar e cumprir o conjunto de dispositivos legais. Outro aspecto não menos importante identificado foi a falta de legitimidade que esta política ambiental e os órgãos ambientais encarregados de sua execução fazem prova junto às populações locais. Isto se deve, em grande parte, à falta de entendimento com os atores sociais locais e pelo desconhecimento da realidade socioeconômica da região. Enfim, podemos afirmar que o sucesso de qualquer política ambiental depende de uma integração socioeconômica das populações locais. É evidente que o apoio destas populações a qualquer política ambiental é diretamente relacionado com a satisfação de suas necessidades mais básicas (saúde, alimentação, etc.) e que essa situação está longe de ser alcançada no litoral norte do Paraná.

Algumas questões preliminares referentes, até o presente momento, às estratégias implementadas pelos agricultores familiares localizados na Área de Proteção Ambiental de Guaraqueçaba permitem a elaboração de algumas reflexões tanto de cunho teórico como referentes às possibilidades de contribuição da instituição universitária.

Os principais questionamentos de natureza teórica apontam para a necessidade de aprofundamento de alguns conceitos utilizados no estudo de realidades agrárias fortemente marcadas pela problemática ambiental. O conceito de população tradicional proporcionou, sem dúvida, um importante avanço para o reconhecimento da necessidade da manutenção dos habitantes e sociedades rurais em zonas de preservação ambiental no Brasil. No entanto, corroborada por esta concepção, criou-se toda uma forma de abordar a questão ambiental por parte dos poderes públicos e entidades de preservação ambiental que, além de restringir as possibilidades de desenvolvimento das comunidades locais, criminaliza suas atividades produtivas, provocando um sentimento de rejeição a qualquer ação em prol da preservação da natureza.

Igualmente, cabe salientar que os questionamentos decorrentes desta pesquisa apontam para a necessidade de um aprofundamento da idéia de sustentabilidade. Com efeito, esta idéia pode aportar 
uma importante contribuição à reflexão da problemática de populações tradicionais em áreas de proteção ambiental. Para tanto, deve-se considerar a sustentabilidade como um elemento indispensável e central para a compreensão dos conflitos e adaptações entre os diferentes âmbitos do processo de reprodução (ecológica, social, técnico-produtiva, biodemográfica) protagonizados pelos diferentes atores sociais do meio rural: agricultores, moradores rurais, instituições públicas ligadas ao meio ambiente, ONGs ambientalistas, instituições públicas municipais e estaduais, etc. Esta reflexão nos conduz a considerar, portanto, o conceito de reprodução não somente como uma mera repetição dos requisitos de manutenção de um dado universo natural ou social, mas como portador de historicidade, ou seja, de mudança.

As questões políticas referentes à relação universidade-demanda social, colocadas em evidência no decorrer da realização desta pesquisa, sugerem a continuidade do trabalho de extensão universitária em curso (Zanoni et al.,1998). Igualmente, a ampliação do trabalho de interlocução e mediação permitido por esta aproximação entre a universidade e os atores sociais locais pode ser imputado como uma importante contribuição do programa de pesquisa.

Por fim, cabe salientar que este trabalho permitiu a elaboração de algumas hipóteses relativas à dinâmica social das populações tradicionais do litoral norte do Paraná. Algumas destas hipóteses referem-se às causas do crescimento do número de do- micílios rurais nesta região nas últimas décadas. As primeiras análises deste fenômeno populacional têm revelado que o extrativismo do palmito pode estar ocasionando tal situação. Tal fato pode estar relacionado a um processo de recomposição familiar em decorrência das possibilidades que a atividade de extração propicia em termos de renda monetária, sobretudo quando associada a uma agricultura de subsistência e/ou para venda.

A análise preliminar dos resultados deste trabalho tem revelado que grande parte da população local tem buscado assegurar sua sobrevivência estabelecendo estratégias tanto no âmbito familiar e comunitário como, também, mais amplas, sintonizando-se com as possibilidades oferecidas por atores sociais e demandas externas. Esta situação parece configurar, portanto, uma realidade bastante distante daquela sugerida pela categorização inicial destas populações como populações tradicionais. Assim, podemos considerar que a maior parte da população local, que tem acesso à terra, tem reconstruído constantemente a sua identidade social em novos patamares, mas mantendo a sua identidade de agricultores. Portanto, restam ainda inúmeras questões acerca destas populações locais, não somente no sentido de aprofundar o conhecimento das suas estratégias de sobrevivênvia em uma Área de Proteção Ambiental como, igualmente, identificando como tais estratégias se articulam com as estratégias comuns a agricultores familiares de outras regiões.

DIEGUES, Antônio Carlos S. Populações Tradicionais em Unidades de Conservação: o Mito Moderno da Natureza Intocada, in: VIEIRA, Paulo Freira; MAIMON, Dália (orgs.) As Ciências Sociais e a Questão Ambiental. RJ/ PA: APED, NAEA, 1993.

DIEGUES, A. C. S. O mito moderno da natureza intocada. São Paulo: Núcleo de Apoio à Pesquisa sobre Populações Humanas e Áreas Úmidas Brasileiras/USP, 1994. 163 p. DUBY, Georges. Les trois ordres ou l'imaginaire du féodalismo. Paris: Gallimard, 1978. 
GIDDENS, Anthony. A Constituição da Sociedade. São Paulo: Martins Fontes, 1989.

GIDDENS, Anthony. As Conseqüências da Modernidade. São Paulo: Editora Unesp, 1991.

GIDDENS, Anthony. Para Além da Esquerda e da Direita. São Pauilo: Editora Unesp, 1997.

GODELIER, Maurice. L'Idéel et le Matériel. Paris: Fayard, 1984.

GODOY, A. M. G. Um olhar sobre a cidade de Paranaguá: Os impactos sócio-ambientais das mudanças portuárias. Tese de Doutorado em Meio Ambiente e Desenvolvimento, UFPR, Curitiba, 1998.

IPARDES. A.P.A. de Guaraqueçaba: caracterização socioeconômica dos pescadores artesanais e pequenos produtores rurais. Curitiba, Brésil: IPARDES, 1989. 87 p.

IPARDES - IBAMA. Macrozoneamento da A.P.A. de Guaraqueçaba. Curitiba, Brésil: IPARDES - IBAMA, 1990. 254 p.

LEIS, Hector. Ambientalismo: um projeto realista-utópico para a política ambiental, in: VIOLA, E. et al. Meio Ambiente, Desenvolvimento e Cidadania: desafio para as Ciências Sociais. Florianópolis: Cortez, Editora da UFSC, 1995.

MIGUEL, L. A. Formation, évolution et transformation d'un système agraire dans le sud du Brésil (littoral nord de l'État du Paraná): une paysannerie face à une politique de protection de l'environnement: "Chronique d'une mort annoncée?". Tese de Doutorado, INA-PG, Paris, 1997, 313p. + anexos

MIGUEL, L. A.; ZANONI, M. M. Impactos socioeconômicos de uma política de proteção ambiental sobre os agricultores familiares e produtores rurais do litoral norte do Estado do Paraná. In: AGUIAR, D. R. D. ; PINHO, J. B. Agronegocio Brasileiro: Desafios e perspectivas. $36^{\circ}$ Congresso Brasileiro de Economia e Sociologia Rural. Artigos e Resumos. Brasília: SOBER, 1998, p. 179-191.
MIGUEL, L. A.; ZANONI, M. M. Reflexões sobre a hostilidade das populações locais frente à implantação de políticas regionais de proteção ambiental no Brasil: o caso da A.P.A. de Guaraqueçaba - Paraná. II Simpósio Internacional de Qualidade Ambiental. Anais..., Porto Alegre, 1998, p.620-626.

MIGUEL, L. A.; ZANONI, M. M. Práticas agroflorestais, políticas públicas e meio ambiente: o caso do litoral norte do estado do Paraná. Extensão Rural, DEAR/CPGExR CCR - UFSM. Ano V - jan-dez 1998, p. 9-23.

PRIGOGINE, Ilya; STENGERS, Isabelle. A Nova Aliança. Brasília: Editora UnB, 1991.

RAYNAUT, Claude. Histoire des Interactions sociétés/ nature - projet de recherche. CNRS-UPRES, Bordeaux II, França, p. 26, 1999.

RAYNAUT, C. et al. Sustentabilidade e mudança: História das transformações sociais e ecológicas no litoral do Paraná (Brasil). X World Congress of Rural Sociology/XXXVIII Congresso Brasileiro de Economia e Sociologia Rural, IRSA/ SOBER, Auburn/Al - Brasília/DF, 2000, p. 1-27 (CD-Rom).

ROUGEULLE, M. D. La crise de la pêche artisanale: transformation de l'espace et destructuration de l'activité - le cas de Guaraqueçaba (Paraná, Brésil). Tese de Doutorado, Université de Nantes, UFR de Géographie, Nantes, 1993. $410 \mathrm{p}$.

S.E.D.U. Coletânea de Legislação Ambiental Federal e Estadual. Governo do Estado do Paraná. Curitiba, S.E.D.U., 1990. 536 p.

ZANONI, M. M.; WALFLOR, M. M.; ROUGEULLE, M. D. Novas modalidades de pesquisa, ensino, extensão: o programa de desenvolvimento sustentável de Guaraqueçaba (Paraná, Brasil) - A universidade e a demanda social das comunidades. Cadernos de Desenvolvimento e Meio Ambiente. Curso de Pós-Graduação em Meio Ambiente e Desenvolvimento - UFPR, Editora da UFPR, Curitiba, 1998, p. 33-54. 